\title{
Identificação e caracterização dos stakeholders do ramo alimentício: um estudo de caso na cidade de Cascavel - PR
}

\author{
Identification and characterization of foods business \\ stakeholders: a case study in the city of Cascavel - PR
}

\author{
Denize Cavichioli ${ }^{1}$, Keila Priscila dos Santos ${ }^{2}$, Aládio Zanchet ${ }^{3}$
}

\section{Resumo}

\begin{abstract}
Este estudo teve como objetivo identificar e classificar os stakeholders mais relevantes do ramo de restaurantes na cidade de Cascavel - PR. A pesquisa desenvolveu-se a partir de uma abordagem qualitativa, caracterizada através dos procedimentos como estudo de caso e quanto aos objetivos como descritiva. Aplicou-se entrevistas semiestruturadas com representantes de três stakeholders da cidade, o sindicato com nome fictício de Sindirestaurantes, o curso de Gastronomia da faculdade com o nome fictício de Educalimentos e um restaurante de porte médio, com o nome fictício de Delícia de Cozinha e Cia Ltda. Identificou-se que os stakeholders do setor alimentício da cidade de Cascavel - PR compreendem os restaurantes, clientes, fornecedores, funcionários, governo, Sindirestaurantes, curso de Gastronomia da faculdade com o nome fictício de Educalimentos, cozinheiros e outros lojistas para aqueles restaurantes que estão localizados em centros comerciais, shoppings e outros lugares em que os restaurantes atraiam clientes para a região. O presente artigo discutiu a aplicação da Teoria dos Stakeholders no ramo de restaurantes e contextualizou entidades que de alguma forma estão relacionadas a este, contribuindo assim para o avanço dessa teoria.
\end{abstract}

Palavras-chave: Stakeholders. Teoria dos Stakeholders. Restaurantes.

\begin{abstract}
This study aimed to identify and rank of the most relevant stakeholders of restaurants business in the city of Cascavel - PR. The research was developed from a qualitative approach, as the procedures it was a case study and objectives were descriptive. It was applied semi-structured interviews with the representatives of three stakeholders in the city, the syndicate with the fake name of Sindirestaurantes, the course of gastronomy in the college with the fake name of Educalimentos and a local restaurant with the fake name of Delicious Kitchen and Cia Ltda. It was identified that the stakeholders in the food sector in the city of Cascavel - PR include restaurants, customers, suppliers, employees, the
\end{abstract}

\footnotetext{
${ }^{1}$ Mestrado em Contabilidade pela Universidade Estadual do Oeste do Paraná (Unioeste), Cascavel, Paraná, Brasil. Professora da Pontifícia Universidade Católica do Paraná (PUC-PR), Paraná, Brasil. Professora da Universidade Estadual do Oeste do Paraná, Cascavel, Paraná, Brasil. E-mail: denize.cavichioli@gmail.com

${ }^{2}$ Mestrado em Contabilidade pela Universidade Estadual do Oeste do Paraná, Cascavel, Paraná, Brasil. Professora do Centro Universitário Univel, Cascavel, Paraná, Brasil.

${ }^{3}$ Doutorado em Controladoria e Contabilidade pela Faculdade de Economia, Administração e Contabilidade da Universidade de São Paulo (FEA-USP), São Paulo, São Paulo, Brasil. Professor e Pesquisador da Universidade Estadual do Oeste do Paraná, Cascavel, Paraná, Brasil.
} 
Government, Syndicate of hotels, restaurants, bars and similar in the West of Paraná, Sindirestaurantes, gastronomy course, cooks and other business places that are located in shopping centers, malls and other places where restaurants attract customers to the area. This article discussed the application of the theory of stakeholders in the restaurant business and contextualized organizations that are somehow related to them, and, consequently contributing to the advancement of this theory.

Keywords: Stakeholders. Stakeholders theory. Restaurants.

\section{Introdução}

Em épocas passadas as organizações eram muito simples e grande parte dos empreendedores fundaram suas empresas para serem administradas pelas próprias famílias, de forma básica. A preocupação do gestor ou dono da empresa era essencialmente a satisfação dos fornecedores e clientes para conseguir que seu negócio fosse bem sucedido (FREEMAN, 1984). Freeman (1984) ressalta também que o desenvolvimento do processo de produção, novas tecnologias, fatores demográficos, entre outros, fizeram com que as organizações se tornassem maiores e de caráter econômico.

As empresas que mudaram para um maior nível de complexidade, segundo Freeman (1984), passaram a ter que se preocupar com o ambiente externo. Em decorrência disso, os gestores passaram a criar estratégias específicas para cada tipo de grupo que influencia o rendimento da organização, o que exigiu deles uma melhor compreensão sobre a identidade e as características desses grupos, chamados de stakeholders.

Harrison e Bosse (2013) sugerem que as empresas conseguem atingir níveis altos de competitividade e criam maior valor se elas tratam seus stakeholders de forma generosa. Harrison, Freeman e Abreu (2015) complementam afirmando que os stakeholders que são bem tratados tendem a ser recíprocos com atitudes positivas, como, por exemplo, o aumento da compra dos produtos ou serviços (clientes), possibilidade de um melhor incentivo fiscal (comunidade), possibilidade de melhores termos de financiamentos (instituições financeiras), trabalho árduo e lealdade à organização, mesmo durante períodos difíceis (empregados), entre outros.
Estudos anteriores sobre o tema têm apresentado importantes resultados para o avanço do conhecimento nessa área. Costa et al. (2012), por exemplo, analisaram as características e as ações estratégicas dos stakeholders do setor de turismo da cidade de Guarulhos - SP, a partir da Diretoria de Turismo da cidade. Os resultados permitiram compreender melhor a percepção dos stakeholders locais e regionais, sua forma de atuação, integração com a administração e articulação dos mesmos em âmbito municipal eregional. Em outro estudo Guizi, Santos e Wada (2014) buscaram compreender as relações entre hotéis e seus stakeholders como fator de competitividade para a captação e a realização de eventos corporativos. Os autores concluíram que o relacionamento entre stakeholders é fator de competitividade para captação de eventos corporativos. No estudo de Cintra et al. (2015), os autores buscaram identificar e caracterizar os stakeholders do turismo local de Londrina - PR, a partir da perspectiva da Administração Pública, no qual foram identificados os interessados no campo de turismo e as entidades envolvidas.

Devido à importância do setor alimentício no ramo de restaurantes na cidade de Cascavel $\mathrm{PR}$, e pelo fato de movimentar parcela considerável da economia do município, há a necessidade de identificação dos principais interessados nos setores de atividades, visto que as organizações empresariais têm a possibilidade de obter consequentes benefícios com isso.

Nesse sentido, considerando a inexistência de estudos sobre os stakeholders do setor alimentício no ramo de restaurantes da cidade de Cascavel PR, este estudo busca responder a seguinte questão: quais são os stakeholders do setor alimentício no ramo de restaurantes da cidade de Cascavel - PR considerados mais relevantes para a atividade? 
Sendo assim, o estudo tem como objetivo identificar e classificar os stakeholders mais relevantes do ramo de restaurantes na cidade de Cascavel - PR.

O estudo justifica-se sob a perspectiva prática ou profissional, por investigar os interessados do setor alimentício no ramo de restaurantes da cidade de Cascavel - PR, haja vista que estes têm influências em possíveis decisões sobre o andamento das atividades do setor. Sob a perspectiva teórica, o estudo justifica-se por acrescentar resultados à Teoria dos Stakeholders. Ainda, numa perspectiva acadêmica, a pesquisa busca contribuir para a pesquisa científica na área de Teoria da Contabilidade.

Este artigo foi estruturado de forma a conduzir, na próxima seção, uma breve exposição sobre os stakeholders, de acordo com a Teoria dos Stakeholders. A metodologia utilizada, bem como suas tipologias, é exposta na terceira seção. $\mathrm{Na}$ quarta seção são apresentados e discutidos os dados obtidos com a pesquisa empírica. As considerações finais são apresentadas na quinta seção e buscam responder à pergunta de pesquisa, além de apresentar as limitações e sugestões para futuras pesquisas.

\section{Fundamentação Teórica}

Visando aprofundar a reflexão sobre o tema, nesta seção são discutidos os seguintes assuntos: contexto histórico da Teoria dos Stakeholders, seus principais conceitos e abordagens e as categorias dos stakeholders.

\section{Contexto histórico da Teoria dos Stakeholders}

A abordagem estratégica dos stakeholders surgiu em meados de 1980, tendo como elemento propulsor a publicação do livro de Edward R. Freeman, Strategic Management - A Stakeholder Approach, em 1984. É importante ressaltar aqui que o ímpeto por trás dessa abordagem foi a tentativa de construir uma estrutura que era sensível às preocupações dos gestores que estavam sendo afetados por níveis sem precedentes de turbulência ambiental e de mudanças (FREEMAN; MCVEA, 2001).

A palavra stakeholders, que traduzida para o português quer dizer partes interessadas, apareceu pela primeira vez na literatura em um memorando interno do Instituto de Pesquisa de Stanford, em 1963, sendo que o termo foi criado para generalizar a noção de acionista como o único grupo a quem a gestão precisa auxiliar (FREEMAN, 1984). Assim, o autor assevera que o conceito de stakeholders foi inicialmente definido como "grupos sem cujo apoio a organização deixaria de existir" e no qual estavam originalmente incluídos os acionistas, empregados, clientes, fornecedores, credores e a sociedade.

Mais tarde, no ano de 1978, Pfeffer e Salancik revisaram a literatura e construíram um modelo de interação entre a organização e o ambiente, o qual depende de uma análise dos recursos da organização e da dependência relativa da organização sobre os fatores ambientais para fornecer esses recursos. Embora eles não tenham definido explicitamente stakeholders, eles afirmam que as organizações sobrevivem se conseguirem ser eficazes, e a sua eficácia deriva da gestão de demandas, principalmente as demandas de stakeholders, sobre a qual as organizações dependem de recursos e apoio (FREEMAN, 1984).

\section{Principais conceitos e abordagens da Teoria dos Stakeholders}

A Teoria dos Stakeholders, em sua essência, é sobre a criação de valor. No entanto, os gestores tendem a ter diferentes perspectivas sobre quem deve compartilhar o valor que é criado (HARRISON; FREEMAN; ABREU, 2015). As pessoas envolvidas na criação de valor são responsáveis precisamente por esses grupos e indivíduos que podem afetar ou ser afetadas por suas ações, os stakeholders. Isso, para a maioria dos negócios, significa prestar atenção, pelo menos nos clientes, colaboradores, fornecedores, comunidade e financiadores (FREEMAN et al., 2010). 
De acordo com Harrison, Freeman e Abreu (2015), a Teoria dos Stakeholders é necessária para fornecer uma perspectiva mais equilibrada nos objetivos das organizações e no gerenciamento para alcançá-los. As empresas podem ser gerenciadas tendo em conta não só os interesses dos proprietários, mas também os interesses dos outros stakeholders, dando origem ao gerenciamento destes (RETOLAZA, ROQUEÑI; SAN JOSE, 2015).

De maneira complementar, Freeman et al. (2010) afirmam que a Teoria dos Stakeholders é, fundamentalmente, uma teoria sobre como o negócio funciona no seu melhor, e como ele poderia funcionar.

De acordo com Freeman (1984), a literatura em Teoria da Organização não chega, em sua maior parte, a produzir um quadro para a definição e implementação da direção em organizações. Em sua maioria, ela tenta ser puramente descritiva e há pouco explicado sobre o "ajuste" entre a literatura da Teoria da Organização e a literatura de planejamento estratégico, da mesma forma que entre a Teoria de Sistemas e a literatura corporativa de responsabilidade social.

Ressalta-se que não basta direcionar objetivos de uma organização apenas para uma determinada classe ou indivíduo interessado. Freeman (1984) afirma que, a fim de serem bem sucedidos, os gestores têm que satisfazer simultaneamente os proprietários, os trabalhadores, seus sindicatos, fornecedores e clientes.

Sobre a definição e identificação dos stakeholders, Friedman e Miles (2006) afirmam que existe uma relação clara entre as duas e que a forma mais comum de classificar os stakeholders é a de considerar grupos de pessoas que influenciam as corporações, notando que os grupos mais comuns de stakeholders a serem considerados são: acionistas, clientes, fornecedores e distribuidores, empregados e comunidades locais. Os autores ressaltam ainda que a questão-chave é saber se os stakeholders se limitam àqueles que são cruciais para a consecução dos objetivos corporativos ou se eles são meramente qualquer entidade afetada por ações da empresa, especialmente se este último inclui ações alternativas que as corporações poderiam ter tomado a fim de atingir seus objetivos, mas não foram escolhidos.

A existência do papel do stakeholder não significa que todos os membros desse papel têm os mesmos interesses (RETOLAZA; ROQUEÑI; SAN JOSE, 2015). Um dos aspectos mais importantes da Teoria dos Stakeholders, que muitas vezes é negligenciado, é que os stakeholders não são genéricos, nem são homogêneos dentro dos grupos. Ou seja, os clientes de uma organização normalmente não são os mesmos que os de uma outra empresa, e mesmo que eles sejam do mesmo setor e dentro de grupos de clientes, um cliente não vai ter os mesmos valores, desejos, ou função de utilidade igual a de outros clientes (HARRISON; FREEMAN; ABREU, 2015).

Stakeholders são definidos em termos de realização dos objetivos da organização. Alguns podem ser simultâneos na empresa, alguns podem ser reconhecidos como stakeholders, mas não têm qualquer influência, enquanto outros podem ter influência, mas sem participação (FRIEDMAN; MILES, 2006).

\section{Categorias dos stakeholders}

As categorizações analíticas são um conjunto de métodos em que a classificação dos stakeholders é realizada por aqueles que analisam com base em suas observações do fenômeno em questão e incorporam alguma expectativa teórica sobre a maneira de como um sistema trabalha (REED et al., 2009). A identificação do número de categorias de grupos de stakeholders é limitada pela amplitude em que os grupos foram definidos (FRIEDMAN; MILES, 2006).

Identificar as partes interessadas, segundo Reed et al. (2009), geralmente é um processo interativo, e durante esse processo os stakeholders são adicionados em uma análise contínua. Por exemplo, usando a opinião de especialistas, grupos de foco, entrevistas semiestruturadas, amostragem bola de neve etc. $\mathrm{O}$ autor assevera que 
se os limites do próprio fenômeno são claramente definidos, em seguida, os stakeholders podem ser relativamente fáceis de serem identificados. Na Figura 1 há uma representação acerca desse processo de identificação, onde os três primeiros itens representam a racionalidade, seguido pela tipologia e pelos métodos.

Figura 1 - Representação esquemática do processo de identificação dos stakeholders.

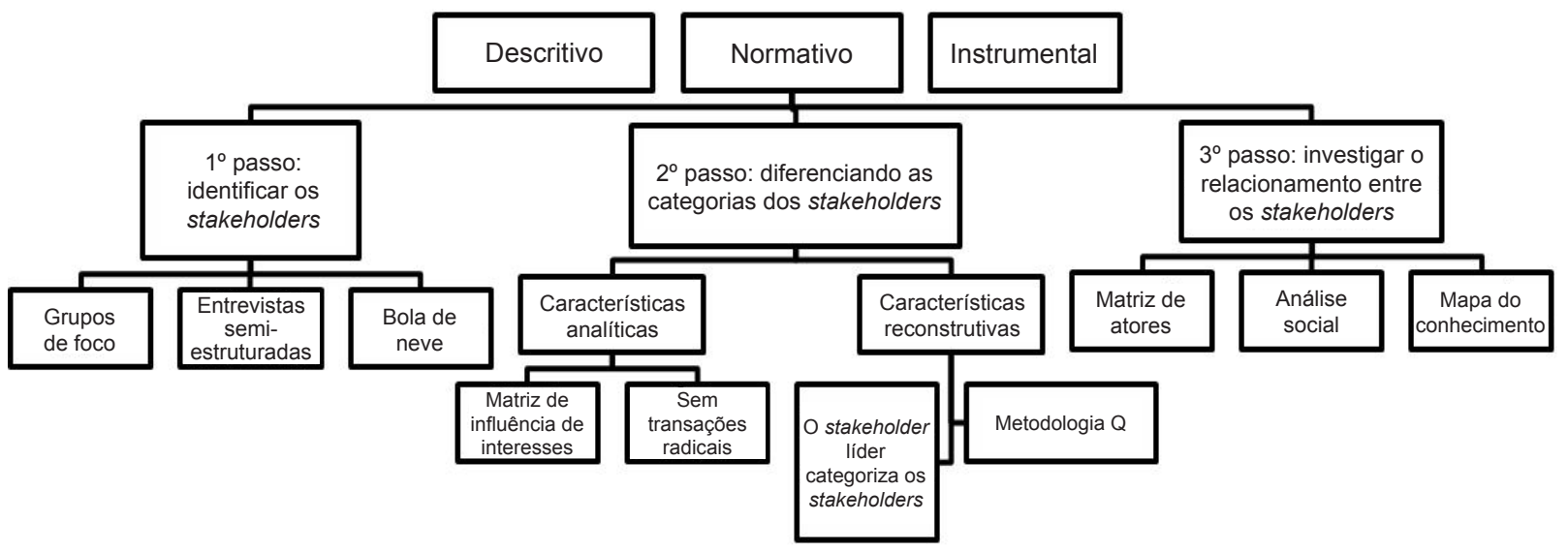

Fonte: Reed et al. (2009, p. 1936, tradução livre)

Mitchell, Agle e Wood (1997) definem poder, legitimidade e urgência, conforme são atributos para os stakeholders, dividindo-os em expostos no Quadro 1.

Quadro 1 - Atributos dos stakeholders.

\begin{tabular}{|c|l|}
\hline Atributo & \multicolumn{1}{c|}{ Relação com stakeholders } \\
\hline Poder & $\begin{array}{l}\text { Uma organização/indivíduo tem o poder, na medida em que tem ou pode ter acesso } \\
\text { coercitivo, utilitário ou meios normativos, para impor sua vontade no relacionamento. }\end{array}$ \\
\hline Legitimidade & $\begin{array}{l}\text { A noção de "legitimidade" refere-se vagamente a estruturas ou comportamentos } \\
\text { geralmente aceitos e esperados socialmente, mas muitas vezes éacoplada implicitamente } \\
\text { com o poder, quando as pessoas tentam avaliar a natureza dos relacionamentos na } \\
\text { sociedade. }\end{array}$ \\
\hline Urgência & $\begin{array}{l}\text { Existe apenas quando estiverem preenchidas duas condições: (1) quando um } \\
\text { relacionamento ou reclamação é de natureza urgente e (2) quando esse relacionamento } \\
\text { ou reivindicação é importante ou crítica para o stakeholder. Combinada com a } \\
\text { legitimidade, promove o acesso aos canais de tomada de decisão, e em combinação } \\
\text { com o poder, incentiva a ação unilateral dos stakeholders. Em combinação com ambos, } \\
\text { desencadeia reconhecimento recíproco e de ação entre os stakeholders e gestores. }\end{array}$ \\
\hline
\end{tabular}

Fonte: Mitchell, Agle e Wood (1997, p. 872, tradução livre)

Depois de apresentados os atributos, é possível definir seus grupos de classes. Mitchell, Agle e Wood (1997) classificam os stakeholders em latentes, expectantes e definitivos.
O grupo dos latentes, de acordo com Mitchel, Agle e Wood (1997), compreende os stakeholders que não são susceptíveis a dar qualquer atenção ou reconhecimento para a empresa, tendo baixa 
relevância, e apenas um dos atributos poder, legitimidade e urgência é percebido pelos gestores. Esse grupo pode ainda ser dividido em:

a) adormecido: que possui somente o atributo poder;

b) discricionário: possui apenas o atributo legitimidade;

c) exigente: que possui apenas o atributo urgência.

Já o grupo dos expectantes é constituído pelos stakeholders que têm dois dos atributos poder, legitimidade e urgência, explicam Mitchel, Agle e Wood (1997). O nível de engajamento entre os gestores, e este é mais elevado, e a relevância dos interessados será moderada.
São divididos em:

a) dominante: que possui os atributos poder e legitimidade;

b) dependente: que possui os atributos legitimidade e urgência;

c) perigoso: que possui poder e urgência.

O terceiro e último grupo é formado pelos stakeholders definitivos, que são formados por aqueles que contêm os três atributos: poder, legitimidade e urgência. Qualquer stakeholder expectante pode se tornar definitivo através da aquisição definitiva do atributo em falta (MITCHEL; AGLE; WOOD, 1997).

Essas classificações podem ser observadas com detalhes na Figura 2.

Figura 2 - Grupos de classes dos stakeholders.

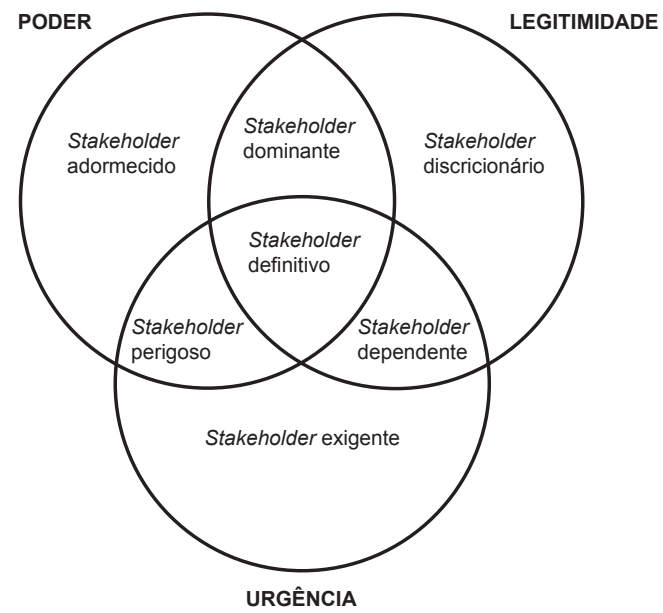

Fonte: Mitchell, Agle e Wood (1997, p. 874, tradução livre)

Após a exposição do contexto histórico da Teoria dos Stakeholders, seus principais conceitos e abordagens, bem como as categorias dos stakeholders, na próxima seção serão tratados os procedimentos metodológicos utilizados para a pesquisa.

\section{Metodologia}

As pesquisas descritivas têm como objetivo principal a descrição das características de determinada população ou fenômeno ou o estabelecimento de relações entre variáveis (GIL,
1989). Portanto, a metodologia utilizada quanto ao objetivo é descritiva.

Em relação aos procedimentos, a pesquisa é caracterizada como estudo de caso. De acordo com Raupp e Beuren (2012), esse tipo de pesquisa caracteriza-se principalmente pelo estudo concentrado em único caso. Na pesquisa em questão, esse caso refere-se ao ramo de restaurantes da cidade de Cascavel - PR.

Quanto à abordagem do problema, a pesquisa é caracterizada como qualitativa. Richardson (1999) afirma que a abordagem qualitativa caracteriza-se por descrever a 
complexidade de determinado problema, analisar a interação de certas variáveis, compreender e classificar processos dinâmicos vividos por grupos sociais, além de contribuir no processo de mudança de determinado grupo e possibilitar, com maior nível de profundidade, a compreensão das particularidades do comportamento dos indivíduos.

A pesquisa foi realizada na cidade de Cascavel - PR, no ramo alimentício, com foco nos restaurantes que atendem em horário de almoço. Dois processos de amostragem utilizados em pesquisa qualitativa foram articulados para a construção: intencional e conveniência. A escolha dos estabelecimentos a serem entrevistados ocorreu através da Associação Comercial e Industrial de Cascavel (ACIC), que foi selecionada como ponto de partida por ser um meio de representação dos empresários e estarem voltados ao desenvolvimento econômico da cidade. A partir da indicação dessa associação, foi entrevistado primeiramente o presidente do Sindirestaurantes, posteriormente a coordenadora do curso de Gastronomia da Educalimentos, sendo esta a única instituição da cidade que ministra esse curso e, por último, a proprietária de um restaurante de porte médio, com o nome fictício de Delícia de Cozinha e Cia Ltda. A escolha do restaurante foi feita de forma intencional, levando-se em consideração o acesso às informações e a importância do estabelecimento para o local.

A coleta de dados para a realização da pesquisa foi feita através de entrevistas semiestruturadas, sendo que o roteiro foi baseado no modelo de Cintra (2013). O instrumento é composto por quatorze perguntas abertas, e dividido em quatro partes:

1) Identificação dos stakeholders, interesses e características, constituída por cinco perguntas;

2) Formulação de estratégias, por parte dos stakeholders, contendo três perguntas;

3) Participação e ação dos stakeholders locais, com duas questões e;

4) Identificação da dependência dos stakeholders, apresentada com quatro questões.
A aplicação das entrevistas ocorreu no mês de novembro de 2015, sendo que foram aplicadas pessoalmente, gravadas e posteriormente transcritas para melhor aproveitamento das informações. A partir da coleta de dados buscou-se identificar os stakeholders do ramo de restaurantes e suas características para posterior categorização.

\section{Análise dos Resultados}

Nesta sessão são apresentados e analisados os dados e informações obtidos com a investigação empírica. A análise dos stakeholders está segregada em três subseções, conforme orienta Reed et al. (2009), o qual afirma que os trabalhos que utilizam a Teoria dos Stakeholders devem seguir as seguintes etapas: 1) identificação; 2) características; e 3 ) categorização.

Para a coleta das informações sobre os stakeholders do ramo de restaurantes na cidade de Cascavel - PR foi realizada uma explicação prévia para cada entrevistado, sobre o tema stakeholders, juntamente com alguns exemplos, com o objetivo de proporcionar uma melhor compreensão, e consequentemente obter a colaboração dos mesmos com o objetivo da pesquisa.

A investigação foi feita através de perguntas abertas, na qual o entrevistado teve a liberdade para falar abertamente sobre o assunto, e posteriormente foram extraídas as informações necessárias para a pesquisa. Não foi apresentada ao entrevistado nenhuma lista de sugestões de stakeholders para ser hierarquizado.

\section{Identificação dos stakeholders}

A investigação inicial da pesquisa foi baseada em perguntas onde os respondentes deveriam identificar os stakeholders, colocá-los em uma ordem hierárquica de importância, e justificar suas escolhas.

Para identificação dos stakeholders investigou-se inicialmente o entendimento do Sindirestaurantes, que devido ao fato deste ser o órgão que elabora regras e cria convenções que 
regulamentam o funcionamento dos restaurantes da região, composta por 34 municípios, incluindo a cidade de Cascavel - PR, foi reconhecido como o principal stakeholder do setor. O próprio entrevistado comentou sobre a importância dos sindicatos no ramo, conforme a seguir:

"Os sindicatos, tanto o do ramo quanto o dos colaboradores, denotam importância no sentido em que são responsáveis pela elaboração de algumas regras e convenções, de forma a regulamentar a execução das atividades".

Através de entrevista com o presidente da entidade, foram identificados sete stakeholders do ramo, como sendo os mais relevantes. De acordo com o entrevistado os clientes são os principais, conforme evidência coletada durante a entrevista:

"Os clientes são a razão principal pela qual o ramo existe; representam a receita dos restaurantes e sem os quais todo o ciclo e os demais stakeholders não existiriam".

Outro stakeholder destacado durante a entrevista foi o grupo de funcionários. Segundo Harrison, Freeman e Abreu (2015), os funcionários que são bem tratados pela empresa tendem a ter atitudes positivas recíprocas e permanecem leais às empresas. Segundo o presidente do Sindicato, eles são importantes stakeholders, o que pode ser constatado no seguinte trecho:

Os funcionários são importantes porque todo estabelecimento precisa deles para funcionar. Além disso, estão ligados à qualidade do restaurante, tanto na questão do preparo dos alimentos, quanto no atendimento direto com clientes. Os clientes buscam uma boa alimentação e um bom atendimento, e os colaboradores estão diretamente ligados a essas exigências.

O entrevistado deu importância para outros stakeholders, entre eles estão o curso de Gastronomia e o governo, conforme as evidências a seguir:

O curso de Gastronomia é importante porque ele hoje forma profissionais que normalmente não vão trabalhar como funcionários, a grande maioria torna-se empreendedor, sendo importante para a evolução do ramo (presidente do Sindirestaurantes).

O governo, através de suas ações, pode trazer beneficios ou maleficios para o ramo de restaurantes (presidente do Sindirestaurantes).

Quanto ao governo, a opinião do entrevistado vai de encontro com a literatura, no estudo em que os autores Harrison, Freeman e Abreu (2015) afirmam que um bom relacionamento com as empresas pode trazer incentivo fiscal e outros tipos de benefício também.

Através de entrevista com a coordenadora do curso de Gastronomia da Educalimentos, foram identificados alguns stakeholders do ramo; a entrevistada destacou os restaurantes, conforme evidência:

"Os restaurantes são conhecidos pela sua culinária, a comida com qualidade atrai clientes, e assim, o restaurante mantém a demanda com fornecedores e também seus cozinheiros e outros colaboradores".

A coordenadora do curso tem relacionamento com vários fornecedores em virtude das aulas práticas do curso; ela descreveu a importância desse stakeholder para o ramo:

"Em relação aos fornecedores, o ramo conta com vários deles para suprir as necessidades do curso e dos restaurantes, eles variam de acordo com o tipo de culinária e especialidades de cada um".

$\mathrm{O}$ curso de Gastronomia fornece anualmente mão de obra para o ramo; a entrevistada afirmou a relação dos cozinheiros com o setor alimentício, evidenciada a seguir:

"Os cozinheiros estão ligados intimamente ao curso de Gastronomia e aos restaurantes. $O$ curso de Gastronomia forma profissionais com conhecimento geral, como cozinha básica nacional e internacional".

Por meio de entrevista com a proprietária de um restaurante de porte médio, com o nome fictício de Delícia de Cozinha e Cia Ltda, foram identificados alguns stakeholders do ramo; a única entrevistada tem uma visão diferente e cita um stakeholder denominado "lojistas", que apesar de 
não estar diretamente ligado ao ramo, também foi visto como um, conforme a evidência:

"Os outros lojistas para restaurantes localizados em centros comerciais e shoppings são importantes no sentido que, através deles, há circulação de pessoas e pode aumentar a demanda nesses restaurantes".
Cada entrevistado identificou diferentes stakeholders e foi dado um nível de importância divergente para cada um também - pode-se observar as semelhanças e diferenças nas escolhas; a tabela foi organizada de forma hierárquica, considerando a importância atribuída a cada stakeholder, a partir do quadro a seguir:

Quadro 2 - Identificação dos stakeholders.

\begin{tabular}{|l|l|l|}
\hline \multicolumn{1}{|c|}{ Sindicato } & \multicolumn{1}{|c|}{ Curso de Gastronomia } & \multicolumn{1}{c|}{ Restaurantes } \\
\hline Restaurantes & Fornecedores & Fornecedores \\
\hline Clientes & Restaurantes & Clientes \\
\hline Fornecedores & Clientes & Funcionários \\
\hline Funcionários & Cozinheiros & Outros lojistas \\
\hline Sindicato & & \\
\hline Curso de Gastronomia & & \\
\hline Governo & & \\
\hline
\end{tabular}

Fonte: Autores (2018)

Através do Quadro 2, é possível observar que o presidente do Sindicato foi o que mais identificou stakeholders; entre os sete, o que teve maior importância atribuída foi o stakeholder dos restaurantes, e o de menor importância foi o governo. A coordenadora do curso de Gastronomia e a proprietária do restaurante identificaram quatro stakeholders cada uma, e destacaram os fornecedores como principal, mostrando a intensidade deles no ramo, pois além de estarem no topo hierárquico pelas duas entrevistadas, ainda aparecem em terceiro lugar na opinião do presidente do Sindicato.

\section{Características dos stakeholders}

Ao mesmo tempo em que buscou-se a identificação dos stakeholders, procedeuse também à mensuração dos atributos poder, legitimidade e urgência destes, notando que eles foram classificados a partir das descrições feitas pelos entrevistados. Explicou-se previamente o significado dos atributos; alguns stakeholders necessitaram de auxílio do entrevistador para serem classificados, pois os entrevistados não conseguiram identificar os atributos sozinhos. Através das entrevistas puderam ser feitas algumas constatações:

a) restaurantes: possuem legitimidade;

b) clientes: possuem os atributos poder e urgência;

c) fornecedores: possuem poder, urgência e legitimidade;

d) funcionários: possuem legitimidade;

e) cozinheiros: possuem legitimidade;

f) outros lojistas: possuem legitimidade;

g) Sindirestaurantes: possui legitimidade e poder;

h) Sindicato de Hotéis, Restaurantes, Bares e Similares do Oeste do Paraná: possui poder e legitimidade;

i) Educalimentos: possui legitimidade;

j) governo: possui poder e legitimidade.

\section{Categorização dos stakeholders}

No que diz respeito à categorização dos stakeholders, dos dez identificados, cinco stakeholders foram classificados no grupo latentes como discricionários, por possuírem apenas o 
atributo legitimidade, sendo os restaurantes, funcionários, cozinheiros, outros lojistas e o curso de Gastronomia. Não foram encontrados stakeholders adormecidos ou exigentes.

Com relação ao grupo dos expectantes, três deles foram considerados dominantes por apresentarem os atributos poder e legitimidade, sendo o Sindirestaurantes, governo e o Sindicato de Hotéis, Restaurantes, Bares e Similares do Oeste do Paraná; e quanto à categoria perigoso, apenas os clientes se encaixaram, por possuírem poder e urgência. Não foram encontrados stakeholders dependentes.

No que se refere ao grupo de stakeholders definitivos, apenas um deles foi caracterizado como tal, sendo os fornecedores, por possuírem os três atributos abordados na teoria: poder, legitimidade e urgência.

A junção desses grupos, bem como suas categorias, pode ser visualizada na Figura 3.

Figura 3 - Categorização dos stakeholders identificados no ramo de restaurantes de Cascavel - PR.

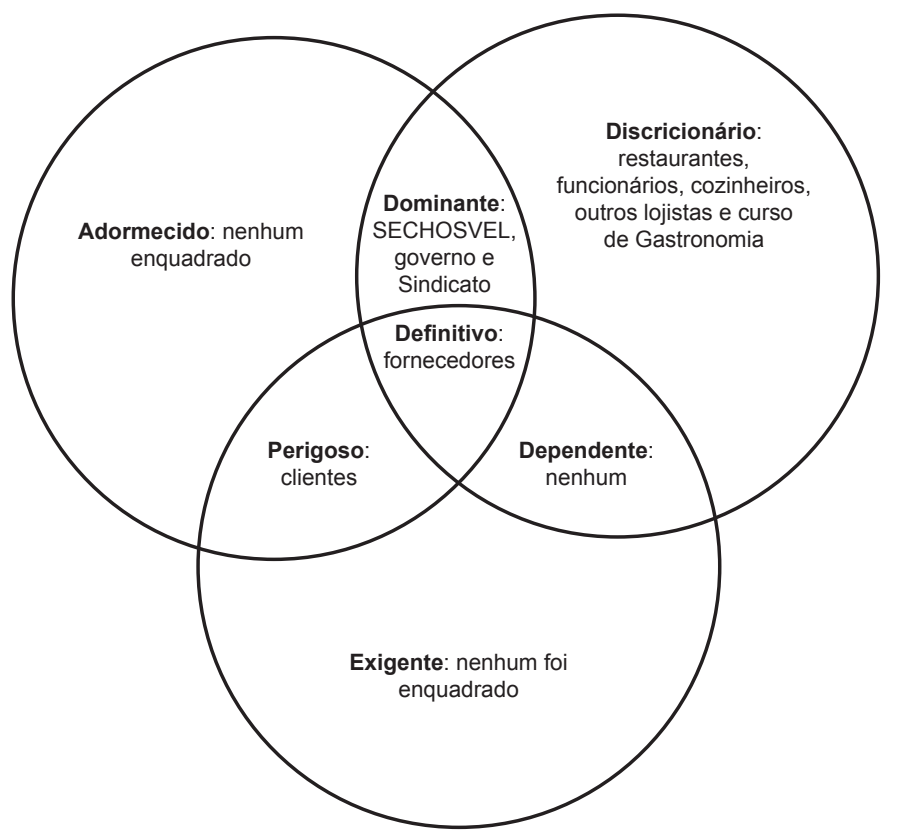

Fonte: Autores (2018)

Sendo o único stakeholder identificado como definitivo, o grupo de fornecedores teve bastante ênfase e foco durante as entrevistas. Constatou-se que suas estratégias envolvem principalmente o seu relacionamento, conforme destaques salientados pelos entrevistados.

Primeiramente precisamos defornecedor; nesse ramo precisamos de um bom relacionamento com eles, precisamos de confiança e resposta rápida. Esse comprometimento dos fornecedores é importantíssimo, pois hoje o custo de armazenamento é muito grande, e pra eu ter esse custo agregado ao meu produto eu terei que passar ele para o cliente, e isso não pode acontecer (proprietária do restaurante Delícia de Cozinha e Cia Ltda).

Os alimentos são comprados conforme as especialidades dos locais; a procura é por alimentos de qualidade; a cada seis meses é feita a revisão dos fornecedores para saber se esses ainda são os melhores em termos de custobeneficio e também para explorar as outras opções que o mercado oferece (coordenadora do curso de Gastronomia).

Observa-se assim o destaque que os fornecedores possuem no setor, sendo indispensável a manutenção de um bom relacionamento com estes, por parte dos demais stakeholders. 


\section{Considerações Finais}

O objetivo desse estudo foi identificar e classificar os stakeholders mais relevantes do ramo de restaurantes na cidade de Cascavel - PR.

Os resultados da pesquisa permitem concluir que os stakeholders do setor alimentício da cidade de Cascavel - PR compreendem os restaurantes, clientes, fornecedores, funcionários, governo, Sindicato de Hotéis, Restaurantes, Bares e Similares do Oeste do Paraná, Sindirestaurantes, curso de Gastronomia da Educalimentos, cozinheiros e outros lojistas para aqueles restaurantes que estão localizados em centros comerciais, shoppings e outros lugares em que os restaurantes atraiam clientes para a região. Os stakeholders identificados vão de encontro com o estudo de Harrison, Freeman e Abreu (2015), os quais afirmam que os stakeholders de um meio serão os indivíduos, grupos ou organizações que têm interesse no processo ou na receita do negócio. Todos os stakeholders do ramo alimentício identificados através das entrevistas se enquadram nessa declaração.

Outra conclusão diz respeito à classificação desses stakeholders, de acordo com a proposição de Mitchell, Agle e Wood (1997). Por possuírem apenas o atributo legitimidade, os stakeholders que se enquadram na categoria latente são os restaurantes, funcionários, cozinheiros, outros lojistas e o curso de Gastronomia; quanto aos expectantes, três deles foram considerados dominantes, por apresentarem os atributos poder e legitimidade, sendo o Sindirestaurantes, governo e o Sindicato de Hotéis, Restaurantes, Bares e Similares do Oeste do Paraná. A última categorização do estudo dos autores Mitchell, Agle e Wood (1997) engloba os stakeholders definitivos, sendo que no presente estudo foi encontrado apenas um, o grupo de fornecedores, devido ao fato de serem necessários os três atributos abordados na teoria: poder, legitimidade e urgência.

Um terceiro aspecto a ser destacado como conclusão do trabalho é o reconhecimento dos atributos da pesquisa de Mitchell, Agle e Wood
(1997) que engloba legitimidade, urgência e poder; nos stakeholders citados no presente estudo foi verificado que a legitimidade está presente em oito dos dez stakeholders, enquanto o poder foi percebido em quatro e a urgência em apenas um.

Este trabalho acrescenta às pesquisas anteriores orientadas pela Teoria dos Stakeholders, um conhecimento sobre sua aplicação no ramo de restaurantes. A pesquisa mostra quem são os stakeholders, seu grau de importância e sua classificação empírica, assim como a possibilidade de criação de estratégicas para os envolvidos e interessados no ramo, fornecendo maior conhecimento a respeito do tema. Também se espera que a pesquisa permita uma melhor compreensão das influências sobre a participação dos stakeholders.

Como limitação deste estudo destaca-se sua aplicação específica ao ramo de restaurantes da cidade de Cascavel - PR, e cujos resultados não podem ser estendidos para outras realidades. Como sugestão de trabalhos futuros, recomenda-se aplicação de questionários para todos os possíveis stakeholders do ramo estudado e, ainda, que outros setores da cidade sejam estudados.

\section{Referências}

CINTRA, R. F.; VIEIRA; S. F. A.; GONÇALVES, L. P.; COSTA, B. K. Turismo local de LondrinaPR: análise a partir da Teoria do Stakeholder. Contextus: Revista Contemporânea de Economia e Gestão, Fortaleza, v. 13, n. 2, p. 149-175, 2015.

CINTRA, R. F. Stakeholders e setor turístico brasileiro: uma investigação na cidade de Londrina/PR. 2013. 166 f. Dissertação (Mestrado em Administração) - Universidade Estadual de Londrina, Londrina, 2013.

COSTA, B. K.; VIEIRA, S. F. A.; BOAVENTURA, J. M. G.; AÑEZ, M. E. M. A influência dos stakeholders na estratégia de órgãos públicos: o caso da diretoria de turismo de Guarulhos/SP. $R G O$ : Revista Gestão Organizacional, Chapecó, v. 5, n. 1, p. 28-41, 2012. 
FREEMAN, E. R.; HARRISON, J. S.; WICKS, A. C.; PARMAR, B. L.; DE COLLE, S. Stakeholder theory: the state of the art. New York: Cambridge University Press, 2010.

FREEMAN, E. R. Strategic management: a stakeholder approach. Boston: Pitman Publishing, 1984.

FREEMAN, E. R.; MCVEA, J. A stakeholder approach to strategic management. Oxford: Blackwell Publishing, 2001.

FRIEDMAN, A. L.; MILES, S. Stakeholder: theory and practice. Oxford: University Press, 2006.

GIL, A. C. Métodos e técnicas de pesquisa social. 2. ed. São Paulo: Atlas, 1989.

GUIZI, A. A.; SANTOS, A. F. L. dos; WADA, E. K. Hotelaria e Stakeholders: competitividade em eventos corporativos - estudo de caso sobre a rede Bourbon de Hotéis e Resorts. In: SEMINÁRIO DA ASSOCIAÇÃO NACIONAL PESQUISA E PÓS-GRADUAÇÃO EM TURISMO, 11., 2014, Fortaleza. Anais [...]. Fortaleza: UECE, 2014. Trab. n. 1458.

HARRISON, J. S.; BOSSE, D. A. How much is too much? The limits to generous treatment of stakeholders. Business Horizons, Bloomington, v. 56, n. 3, p. 313-322, 2013.

HARRISON, J. S.; FREEMAN, E. R.; ABREU, M. C. S. de. Stakeholder theory as an ethical approach to effective management: applying the theory to multiple contexts. Review of Business Management, São Paulo, SP, v. 17, n. 55, p. 859860, 2015.

MITCHELL, R. K.; AGLE, B. R.; WOOD, D. J. Toward a theory of Stakeholder identification and salience: defining the principle of who and what really counts. Academy of Management Review, Ohio, v. 22, n. 4, p. 853-886, Oct. 1997.

RAUPP, F. M. BEUREN, I. M. Metodologia da pesquisa aplicável às ciências sociais. In:BEUREN, I. M. Como elaborar trabalhos monográficos em contabilidade: teoria e prática. 3. ed. São Paulo: Atlas, 2012. p. 76-96.
REED, M. S.; GRAVES, A.; DANDY, N.; POSTHUMUS, H.; HUBACEK, K.; MORRIS, J.; STRINGER, L. C. Who's in and why? A typology of stakeholder analysis methods for natural resource management. Journal of Environmental Management, v. 90, n. 1, p. 1933-1949, 2009.

RETOLAZA, J. L.; ROQUEÑI, M. R.; SAN JOSE, L. An innovative approach to Stakeholder theory: application in Spanish transnational corporations. Review of Business Management, v. 17, n. 55, p. 1007-1020, 2015.

RICHARDSON, R. J. Pesquisa social: métodos e técnicas. 3. ed. São Paulo: Atlas, 1999. 